\title{
CANADIAN SMART CITIES: HEALTH REMEDIES, SIDE EFFECTS AND HARD TO SWALLOW PILLS
}

\author{
By: Andrew Ramsaroop \\ B.A (Honours) Geographic Analysis, Ryerson University, Toronto, Ontario, Canada \\ (2017) \\ Supervised by: Dr. Pamela Robinson, MCIP, RPP
}

\author{
A Major Research Paper presented to Ryerson University \\ In partial fulfillment of the requirements for the degree of \\ Master of Planning in Urban Development (MPI.) \\ Toronto, Ontario, Canada (2019) \\ (C) Andrew Ramsaroop 2019
}




\section{Author's Declaration for the Electronic Submission of a MRP}

I hereby declare that I am the sole author of this major research paper. This is a true copy of the major research paper, including any required final revisions.

I authorize Ryerson University to lend this major research paper to other institutions or individuals for the purpose of scholarly research.

I further authorize Ryerson University to reproduce this major research paper by photocopying or by other means, in total or in part, at the request of other institutions or individuals for the purpose of scholarly research.

I understand that my major research paper may be made electronically available to the public. 


\section{Master of Planning}

in

Urban Development

Ryerson University

(C) Andrew Ramsaroop, 2019

\section{Abstract/Executive Summary}

This research paper investigates the ways in which health was talked about and addressed in Infrastructure Canada's Smart City Challenge. Using the Smart City Challenge applications as the basis of the research, and two as in depth case studies. The main critiques of Smart City Technologies, as well as the concept of Co Creation, and a Performance Measurement Framework were used to identify if the applications could improve, how and if citizens were engaged meaningfully, and where in the healthcare system will the proposed technologies make measurable improvements. Findings from the study indicate there needs to be: greater protections for individual privacy, greater resident engagement/involvement, having health and wellbeing as core tenets of a smart city challenge, and greater protections for indigenous data sovereignty. If these recommendations are taken into account, they will lead to more robust applications in the next iteration Smart City Challenge, and will provide invaluable steps towards greater national data guidelines.

Keywords: Smart Cities Challenge, Health, Urban Planning 


\section{Acknowledgements}

First and foremost, this major research paper would not have been possible without the continuous support of Dr. Pamela Robinson, who had introduced me to smart cities and the Canadian Smart City Challenge, and how the challenge was aiming to shape the future of health in our cities. Her experience and knowledge on civic technologies working to help cities, was fascinating and inspiring. Adding in the complexities around the planners role to advocate for the public interest in the face of the datafication of our cities, inspired much of this research.

I would also like to extend my gratitude to my second reader, Lisa Prime, whose, industry insight, sustainability focus and knowledge on the topic was appreciated.

Finally, I would like to thank my family for the incredible amounts of support they have provided me throughout this research, and my education. To my partner Mark, who supported me in many ways that I could not possibly begin to count, I thank you for always being a great support. To my parents and grandparents, who ensured I always had the tools to learn, and an environment which I could flourish, I owe a lifetime of gratitude.

This MRP was funded, in part, through research grants held by Dr. Pamela Robinson (SSHRC Grants: 892-2018-0046 and 895-2012-1023). 
Chapter 1: Introduction

1.1 Introduction

1.2 Purpose

Chapter 2: Literature Review

2.1 Planning and Defining A Healthy City

2.2 Health determinants

$\begin{array}{ll}2.3 \text { The Healthy Cities Movement } & 7\end{array}$

2.3.1 The Healthy City Movement in Practice $\quad 8$

2.5 Smart City + Health 11

2.5.1 The Healthy Smart City In Canada 12

2.6 Critiques of the Healthy Smart City 13

2.7 Measuring The Potential Impacts of Health Interventions 17

$\begin{array}{ll}\text { 2.7.1 Co Creating Health Benefits } & 17\end{array}$

2.7.2 Performance Measurement Framework 19

$\begin{array}{ll}\text { Chapter 3: Method } & 20\end{array}$

3.1 Scanning the Applications $\quad 20$

3.2 Analyzing the Finalists $\quad 22$

Chapter 4: Evidence and Findings

4.1 Who is Talking about Health? 23

4.2 What Health Issues do the Finalists Hope to Address Using Smart City Tech? 27

4.3 The Finalists $\quad 29$

4.3.1 The City of Edmonton 30

4.3.5 Mohawk Council of Akwesasne $\quad 35$

Chapter 5 Conclusions and Recommendations 40

5.1 Limitations $\quad 40$

5.2 Recommendations for Future Iterations 41

5.3 Recommendation for Future Practice $\quad 45$

$\begin{array}{ll}5.4 \text { Future Research } & 47\end{array}$

5.5 Conclusions $\quad 48$

References $\quad 50$ 


\section{List of Tables}

$\begin{array}{ll}\text { Table 1: Levels of Health Outcome.. } & 21\end{array}$

Table 2: The Analysis, Frameworks and Critiques .. 22

Table 3: Differences in the Definitions of Health.. 24

Table 4: Applications and Levels of Health Outcome categories (\%).. 25

Table 5: Finalist applications + Level of Health Outcome they were Categorized.. 26

Table 6: Finalist Applications and Levels of Health Outcome (\%).. 27

Table 7: Themes of Health in the Primary Health Benefits category.. 28

Table 8: Themes of Health in the Finalist Primary applications.. 28

Table 9: City of Edmonton and Smart City Critiques.. 33

Table 10: MCA and Smart City Critiques.. 38 


\section{List of Figures}

Figure 1: Barton and Grant's (2013) Settlement Health Map.. $\quad 7$

Figure 2: Ramaprasad et al. (2017) Unified Definition of a Smart City.. 10

Figure 3: Mogstad (2017) Levels of Participation in Co-Creation.. 18

Figure 4: CIHI (2013) A Performance Measurement Framework for the Canadian Health System.. 


\section{Chapter 1: Introduction}

\subsection{Introduction}

Beginning In 1854 during the Broad Street cholera outbreak, the City of London saw the birth of modern epidemiology and public health in the works of Dr. John Snow. Since then health has been an important focus for cities, and is responsible for the birth of the profession of urban planning itself; which finds its very roots in the prevention of disease and improving the quality of life for the city's inhabitants. Canadian municipalities not unlike their global counterparts struggle with controlling and preventing illness, disease, and chronic ailments, as well as improving the overall quality of life. This includes the well-being of individuals and communities, their biological factors (diseases or ailments), mental wellness, environmental exposures, life behaviours, social networks, resources (income, housing, food) and access to health services. Access to health services include doctors, hospitals and other western medical resources, as well as traditional medicine and holistic approaches such as those in indigenous communities.

The World Health Organization (WHO) recognizes that, “...the most important asset of any city is the health of its citizens." (World Health Organization Quito, pp.1). It is understood by the $\mathrm{WHO}$ that the accomplishment of positive health outcomes for citizens will have direct impacts on several of the United Nations Sustainable Development Goals, some of which include air pollution, combating non-communicable diseases like obesity and diabetes, and equity (World Health Organization). This is impetus for the study of urban health on a global level, and provides many calls to action for governments. The WHO identifies these as aspects of development in 
developed metropolitan regions where inequities may exist: Built environment, Green environment, Social and economic environment, Food security and quality, and Health services (WHO, 2012).

The equitable and efficient provision of health services is something that is difficult to measure by traditional research methods, and requires new and innovative strategies. Smart City technology proponents promise to actively provide new and innovative solutions to many of these issues by using data to influence policy or initiatives. For example in Manchester, UK CityVerve which is the city's smart city 'demonstrator' is taking a new approach to issues such as chronic disease management, community wellness, and providing neighbourhood support teams (CityVerve, 2019). These interventions are utilizing smart city technologies such as sensors, online platforms and other loT technologies; all of which provide real-time information, and communication to decision makers, stakeholders and citizens.

Despite the buzz of what a smart city can do, or what it could look like it, the implementation of data-driven health policy still somewhat convoluted. In particular, how can municipalities progress from the data collection stage, to analysis and findings, to drafting planning policies that will enforce the changes necessary to improve equitable health provisions and strategies.

\subsection{Purpose}

In 2018 Canadian municipalities were challenged by Infrastructure Canada's Smart Cities Challenge to present an issue in their community that could be addressed through smart city technology solutions. Citizen health and well-being stood out as a strong theme, that multiple municipalities are looking to address in a variety of ways and 
metrics. In all, of the proposals studied there were 25 municipalities and or municipal conglomerates that had health outcomes or improvements to quality of life as their primary goal.

This research seeks to explore the extent to which improvements to citizen health was addressed through the various smart city initiatives. It looks at which municipalities focused primarily on public health improvements, whether or not health will be influenced by the applications which considered health as a secondary outcome, or did not consider it at all. This research will also seek to make recommendations as to how future smart city efforts might focus more on health improvements in accordance to the WHO's focus on urban health equity, the potential effectiveness of the solutions or how they address the major critiques of smart city technology based on analysis. Finally, a list of further research topics will be developed for ongoing analysis and improvements to the Smart City Challenge process, and applications.

The analysis of the Smart City Challenge is crucial to future iterations of the challenge as it will help to build a more dynamic challenge that responds better to issues that applicant cities face, as well as helping to create more robust applications. Although the topic of urban health and planning has been deeply explored by academia for years, and to a smaller extent smart city health in more recent times, there has been limited discussion on how smart city health will be incorporated into local governance, planning and health equity.

As well, the governance of sensitive health data itself, and citizen privacy presents itself as an issue municipalities and other smart city stakeholders must grapple with in an age of security breaches, and external political uncertainties. Exploring the 
ways health should be incorporated into smart city initiatives, and analyzing how this challenge can be an effective vehicle for the implementation of health-based initiatives will position Canada as a country of innovation. Thus, this proves to be an area of research that ought to be studied.

\section{Chapter 2: Literature Review}

\subsection{Planning and Defining A Healthy City}

Measuring the health of a city is difficult due to the equivocality of the term "health" in the first place. The term has changed throughout history to both include and exclude certain factors of wellbeing in people, and overall the contemporary term seems to be more inclusive and holistic. The World Health Organization (WHO) uses several determinants in its "Health Impact Assessment" tool including: the social and economic environment, the physical environment, and the person's individual characteristics and behaviours (WHO, 2018). The WHO also has a more refined version of the definition of health which is, "... is a state of complete physical, mental and social well-being and not merely the absence of disease or infirmity (WHO, 1948).

It is evident that health by this definition, includes measures that go beyond the physical state. This is important specifically in the context of Canadian municipalities which bear the burden of most developed nations, which often face the double edged sword of higher age-related and chronic illness, as well as mental illness, and issues of inequitable access to healthy foods. The WHO also directly charges the field of urban planning with the task of fixing cities citing: 
The main risk factors for NCDs [non-communicable diseases] (tobacco use, alcohol use, physical inactivity, poor diet, exposure to air pollution and chronic stress) are directly influenced by urban design and planning policies that are far beyond the control of individuals. (WHO Quito, 2016)

As the planning profession begins to deal with the effects of rapid urbanization around world and more specifically in Canadian municipalities, they need to enter into communion with land use planning and the health field. It is important that in highly developed cities in the global north, the attention to mitigating disease is not spent merely on acute infection disease, but on the increasingly common chronic age, lifestyle and environmental related diseases. The next step for the 21 st century city is begin integrating planning theory with new and emerging sources of real time data, crowdsourcing and smart city innovation.

\subsection{Health determinants}

Barton and Grant (2013), talk about the multiple health determinants on human settlements, in the form of a settlement health map (figure 1) that was included in WHO's Shaping Neighbourhoods Guide which in turn was inspired by Whitehead and Dahlgren's (1991), figure of the determinants of health. The map demonstrates the interconnectedness of human health on the built environment, the economy, the natural environment, and food security to name a few. Looking at the map gives professionals a better understanding on what can be measured to give us baselines/benchmarks and indicators. As well understanding what is within the realm of urban planning, and what is intra and ultra vires to the realm of Canadian municipalities. Several themes and metrics that are evident are: Lifestyle (diet, physical activity, employment), Community (social 
capital, and networks), Activities (living, playing learning, moving, shopping, and working), Built Environment buildings, places, streets, and routes), and Natural Environment (natural habitats, trees, air, water, land, soils). These categories can be measured in a variety of ways, whether it is the equitable access, quality of service or product, the availability of said service or product or whether there is a sufficient level of provision.

The Government of Canada has created a Pan-Canadian Health Inequalities Data tool which outlines about 12 categories of indicators for health inequalities across the nation (Public Health Canada, 2018). The 12 categories also lie within two broad groups: 'Health Status' and 'Health Determinants' which can also be interpreted as downstream or upstream inequalities respectively. It is advantageous to applicant cities to align with these 12 indicators because underneath each category is the corresponding measure, or data set which measures the category of health inequality as this can provide a national or aggregate baseline, in which to measure progress.

The findings from the Pan-Canadian Inequalities Data tool were summarized in the document Key Health Inequalities in Canada: A national Portrait. The report saw large inequalities for specific groups of people including: Indigenous peoples, racial minorities, people with diverse sexual orientations, immigrants and people who are are differently abled (Public Health Agency of Canada, 2018). Moreover, Indigenous peoples over 15 were much more likely to experience poorer health outcomes than the Canadian Population (Rotenberg, 2016). There are direct relationships between health and a variety of other factors like: income, education, and employment, as well as lifestyle choices such as smoking, drinking and poor eating habits (Public Health 
Agency of Canada, 2016) (Rotenberg, 2016). The report also identified calls to action for improving social determinants of health, which may prove to be useful in the implementation and creation of smart city proposals

The social determinants of health will be used to analyze proposals, and to discern whether proposals intend to make health and wellbeing improvements. It will also be apart of the criteria that will be used to classify them into categories of potential health benefits. It also allows for the identification of possible health benefits in proposals that may not be health oriented or focused.

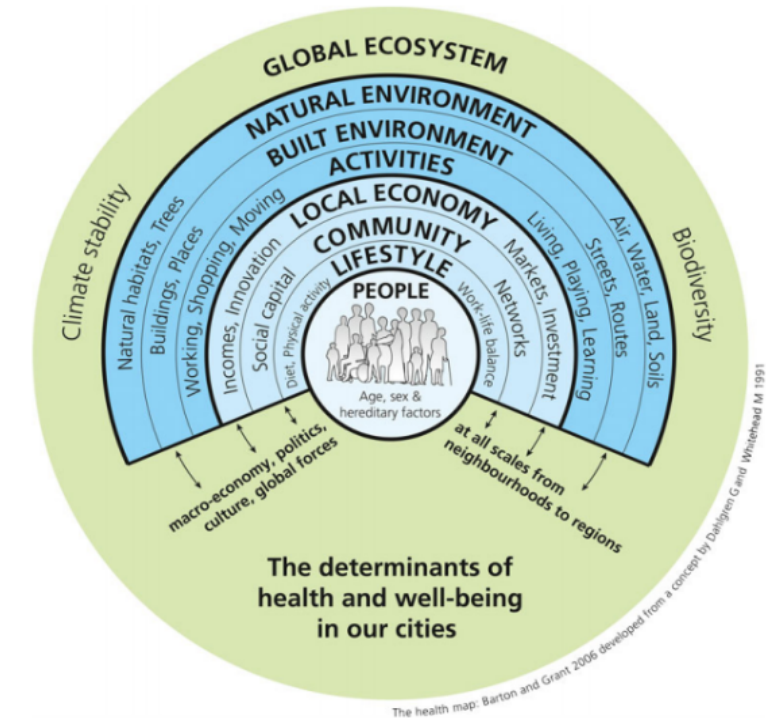

Figure 1: Barton and Grant's (2013) Settlement Health Map

\subsection{The Healthy Cities Movement}

The Healthy Cities Movement is a continuous global initiative, which finds its foundation in the late 1980s after a series of international health conferences by the World Health Organization (Kenzer, 1998). Although the WHO developed the modern movement, it is built upon over centuries of urban planning; this includes Ebenezer 
Howard's Garden City movement in the 1890s, and Sir Benjamin Ward Richardson's "Hygeia: A City of Health" the latter being written after the Great Public Health Act passed in 1875 (Hancock, 1993). In particular, the movement became a vehicle in which city networks began to implement the findings and conclusions of documents such as Health for All, and the Ottawa Charter for Health Promotion (Tsouros, 2015).

Hancock (1993), identifies two of the key takeaways of the movement; First, it identified the historical importance of local government in creating the conditions for health, and they must begin to play a leading role in health promotion. Secondly, the movement evolved in parallel with, and as an application of the promotion of health. Therefore, the movement is most interested in the creating and improving of physical and social environments, and strengthening community resources (ibid). The most important legacies of the Healthy City Movement is the development of social health indicators, which would be able track and measure sustainability, health and equity such as those found in the Toronto Healthy City project which created 136 indicators (Wadell, 1996). The second legacy is the implementation of initiatives and interventions, that have altered the way the governments think and plan for citizen health.

\subsubsection{The Healthy City Movement in Practice}

Understanding the core tenets of the Healthy City movement, is integral to understanding how the movement sought to reform, and charge government and by proxy the planning profession, with having to consider public health in all of its transactions. In the provincial context (Ontario), these can be found through the policy documents such as the Provincial Policy Statement (PPS). The PPS which is the government's high level policy regarding land use planning that acknowledges the 
relationship between environment, economic and social factors. Provincial Policy 1.0, "Building Strong Healthy Communities", has elements of the Healthy City Movement entrenched within its mandate in particular the supporting and promoting of "strong, livable, healthy and resilient communities, protecting the environment and public health and safety..." (PPS 2014, pp.6). Furthermore, 1.1 goes into explaining how "healthy, livable and safe communities" are sustained. Health is further seen in Sections $1.4 .3 \mathrm{~b}$ ), 1.5, 1.6.6.1b), 1.8, 2.2, and is pervasive throughout the rest of the document (PPS 2014, pp 6-23).

The Planning Act requires that all planning matters "shall be consistent with" the PPS. This means decision makers, local governance, planners and the public are all subject to the PPS, and therefore must consider health in every land use decision. Planners in Ontario who are RPP designated in particular are subject the the Ontario Professional Planners Institute (OPPI) Professional Code of Practice. First and foremost is The Planner's Responsibility to the Public Interest, and section 1.3 "acknowledge the inter-related nature of planning decisions and their consequences for individuals, the natural and built environment, and the broader public interest." (OPPI, 2019). This responsibility to the public, charges planners with the duty to always consider the consequences for individuals, which would include the health and wellbeing of the public, when making planning decisions or recommendations. Public health and citizen wellbeing therefore falls into the jurisdiction of local governance and planners, as well the Healthy City Movement is an example of how research moves into practice.

\subsection{Defining the Smart City}


The Smart City has been a buzzword and a hot topic in recent times, and there is a whole swath of literature dedicated to just defining what it is and what it includes.

Finding its roots in Ashton (1999) who coined the term "the internet of things"(lota), was originally meant to be, the open and comprehensive network of intelligent objects that have the capacity to share information, data and resources, reacting and acting to changes in the environment (Madakam et al., 2015). The smart city was the natural genesis from combining the increasingly interconnected nature of computers and data, to the inherent connectedness of the city and its human, built and natural environments.

For the purposes of this research the smart city will be defined by Ramaprasad et al. (2017) Smart City Ontology (figure 1) as it provides a tool for planners and government officials to assess 'smartness' of their cities, provide guidance for new smart city designs, guide cooperative thinking among stakeholders, and unveil gaps in smart city implementation (Ramaprasad et al., 2017).

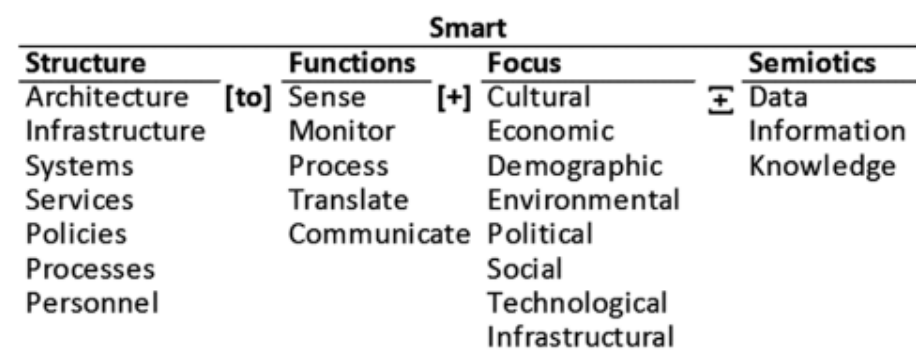

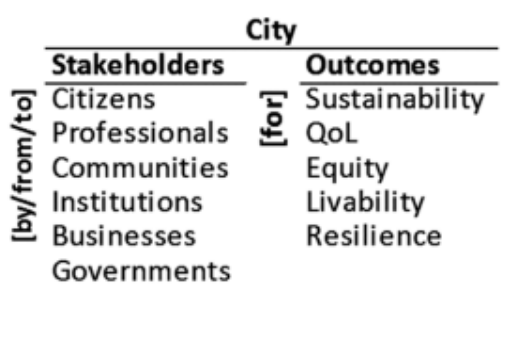

Figure 2: a Unified Definition of a Smart City, The Smart City Ontology Retrieved from Ramaprasad et al. (2017)

This ontology takes into account both the hard infrastructure required for decision making purposes, as well as the human factors such as equity, resilience and quality life which are the ultimate outcomes for employing these technologies. It also acts as an iterative filter that guides the reader through the technological components required for both the smart aspect, and its primary function and role in the city. 


\subsection{Smart City + Health}

The literature surrounding smart city health has previously primarily focused on mobile health or e-health and smart cities as separate domains, but has been combined to create a more synergistic approach in smart health in Solanas et al., (2014). This convergence has allowed for smart health to emerge as a primary component of the smart city and a research interest in its own right.

The Smart City approach provides government and municipalities with a whole new arsenal of tools to combat health and planning problems that plague it. The extent at which policymakers have historically had to make decisions was based on data that was static and a glimpse or sample from a specific period of time. The usage of information communication technologies (ICTs) including complex databases, sensors, computers in e-health has prompted research into feeding into the smart city (Solanas et al., 2014). The smart city technology approaches to closing the health inequity gap, is dynamic in its approaches.

The WHO Healthy Cities programme is directly supported by these smart city initiatives by allowing citizens to become more engaged and empowered through digital infrastructure, all while actively contributing to sustainable development goals (Boulos et al., 2014). In the realm of urban planning the opportunity of smart city applications can have great improvements to: data collection and analysis, the informing of policy decisions, incident prevention, effectiveness, environmental assessment, epidemic control, and cost effectiveness (Solonas et al., 2014). All of these can provide invaluable improvements to access, cost of services, and making long term investments and built form improvements. 


\subsubsection{The Healthy Smart City In Canada}

While the smart city is discussed rather heavily in academia, in real world are only recently beginning to materialize with few large scale project. The current landscape of Smart Health in Canada includes a diversity of key players from both the public and private sectors playing key roles. In the public sector the Government of Canada has begun to have a stake in smart city health initiatives, in particular the daily monitoring of opioid and cannabis consumption in partnership with SCORE (Sewage analysis CORe group - Europe) in the form of wastewater epidemiology (Statistics Canada, 2018). It is expected the results of this study will become a part of Statistics Canada data products that is widely available for public use. This is an example of the current application of the smart city at its most rudimentary level, that will inform future policy and analysis.

Locally in the private sector in conjunction with public agencies, large research studies have been undertaken into integrative healthy communities in particular in Sidewalk Labs' Living Well on the Waterfront: Imagining the Future of CommunityBased Care (2019). This Toronto -Specific research initiative is a part of Sidewalk Labs' Quayside community and is currently ongoing but has identified integrative approaches to community wellbeing, including home tenure-ship, planning for vulnerable populations, planning for the elderly, diversity, high and low tech service delivery, and opportunities for human connections (Sidewalk, 2019). This new community will also potentially employ a large breadth of smart city technologies across their waterfront site, that will interact with the various facets of infrastructure, and add real time monitoring to 
the gauntlet of local policy makers as well as feed information back to Alphabet for analysis.

The diversity in smart health initiatives, should not be limited to conventional health interventions. It should also take into consideration other facets like the relatively low-tech wastewater epidemiology, as well as more high tech and integrative approaches such as building new technological infrastructure to support health and wellbeing as seen in Quayside. As it pertains to the Smart City challenge applicants, it should be analyzed how smart city health data will feed into the overall smart city. The method in data collection, where it will be used and if it serves multiple purposes, should all be considered.

\subsection{Critiques of the Healthy Smart City}

\subsubsection{Privacy and Consent}

The mass collection of personal health information is integral to the operation, and decision making processes that are involved in smart city health projects.

O'Doherty et al. (2016) states that although there are some mechanisms that protect personal data collection, there has been little consideration of the consequences of the " proliferation of highly personal data. Concerns arise when it comes to ethics regarding the increasingly data driven urban environment, such as the absence or the empty practice of notice and consent to either participate or refrain from participation (Kitchin, 2016). Kitchin (2016), argues that notice and consent to participate in the smart city is almost completely absent, and there is no ability to opt out other than to completely avoid an area. This obviously puts people at a disadvantage since the average person 
lacks the knowledge, the physical ability and the resources to be able to effectively become agents, and stewards of their own data footprint.

Bannerman and Orsach (2019) state that smart city technologies often move very quickly from their development stage to the adoption and implementation, often without sufficient political and social deliberations to identify all of the major risks and considerations necessary. In their own research, Bannerman and Orasach (2019) found that $88 \%$ of Canadians were somewhat concerned about their privacy, and $23 \%$ were very concerned. In particular when it came to data use for targeted advertisements, business use, or sale to another party, majority of those who were surveyed objected to the use of their personal data (2019).

\subsubsection{Discrimination}

Big data discrimination is another important factor for consideration of the smart city. Although the initial intent of smart city interventions is often to curb inequities, and allow governments to engage in more dynamic service delivery it has been proposed this can have the opposite effect. Obar and McPhail (2018), state biased algorithms and datasets may change disadvantaged groups eligibility to access certain government programs, or deem vulnerable peoples as too risky an investment. Other instances of big data discrimination include biased policing data, in particular instances of so called 'over-policing' certain neighbourhoods, based on historical crime data, raise human rights issues (Obar and McPhail, 2018).

Bannerman and Orsach (2019) found that $32 \%$ of Canadians would not want their personal data used in policing and $44 \%$, believe it can be used but only if they can ensure certain rights and protections. The same survey also found that those of visible 
minorities or Indigenous identities were more likely to object to data use in policing for a combined total of $42 \%$ (Ibid). This particularly becomes concerning in the case of wastewater epidemiology as is currently being undertaken by Statistics Canada to track cannabis and opioid use, as well as using racial and economic data to profile areas, as this may inadvertently point out certain neighbourhoods that have higher levels of diversity, lower socioeconomic status and higher drug use, which could potentially point law enforcement to disproportionately target these areas.

\subsubsection{Indigenous Data Sovereignty}

Indigenous data sovereignty is also important due to the historic nature of data used against indigenous Peoples for oppression, and unequal power relations (Open North, 2017). In the cases of applications for indigenous communities, and or urban areas whose smart city intervention pay special attention to indigenous peoples; their rights to owning, reporting and collecting their own data must be acknowledged and respected. The report Decolonizing Data by Open North in collaboration with British Columbia First Nations Data Governance Initiative (BCFNDGI) outlines a set of principles of indigenous data sovereignty, that outline diversity, nation-to-nation relations, the non-neutrality of data in the context of colonization, and the understanding of deep traditional history of data collection and dissemination in many Nations just to name a few (Open North, 2017).

Similarly, the First Nations Information Governance Centre (FNIGC) has put together a set of standards called OCAP. OCAP has four guiding principles: Ownership, Control, Access, and Possession (FNIGC, 2014). These four principles are meant to be a response to colonialism and knowledge creation in the context of colonial relations 
(ibid). Much like the NCFNDGI, indigenous peoples are meant to be the creators, curators and stewards on their own data. This is to prevent indigenous peoples from becoming uninformed test subjects, as researchers and the government have treated them historically. It is therefore important that the applicable indigenous Nations are the creators of their own smart city health projects, or are involved with the creation from the very beginning, and not treated as a stakeholders but rather as a driver and decision maker. Participation ought not to be merely symbolic, instead it should be meaningful engagement, and empowerment.

\subsubsection{Data Ownership and Stewardship}

Another major critique of the smart city is the governance, protection and ownership of public data. Inspired by Karl Polanyi's "fictitious commodities" Haggart (2018) argues, that governments have the fundamental role in the governance of personal data in a world of self-interested private actors, and the commodification of private data. Haggart (2018) is not alone is this thinking, Wylie (2018) believes that the government is the preferred steward of data and digital infrastructure due to its accountability to legal mechanisms, and fears the lack of a national data strategy allows for private tech firms to fill the governance vacuum, essentially mimicking government's regulation structures. Wylie (2018), also notes this is not to say however the government itself is immune to misuse of data and tampering from external forces such as lobbyists.

O'Doherty et al. (2016), in particular creates worst case scenarios for breaches and uses in organized health data, including health service stratification, human rights abuses and genetic discrimination, insurance denial and increased premiums. It is also noted that health data use in human rights abuses by governments are not 
unprecedented, however O'Doherty (2016) makes the assertion that health data governance needs to have deep democratic roots, and have robust structures to withstand pressures for untended uses. The primary body of research on data privacy and stewardship is clear in its charging of government to come up with a clear and robust national data governance strategy.

\subsection{Measuring The Potential Impacts of Health Interventions}

\subsubsection{Co Creating Health Benefits}

The idea of co-creation finds its roots in the studies of design, and is described as the collaboration between trained designers and lay people in the initial development process (Sanders \& Stappers, 2007). This is seen as a shift from people being treated as a stakeholder or subject, to them being active partners in the process (ibid). Mogstad (2017) has taken the idea of co-creation and has applied it to innovation and improvements in the public sector, and has shown that it can have higher successes due to increases in: autonomy, ownership, group cohesion, and meaningful experiences. Mogstad (2017) created a figure that demonstrates the levels of participation in co-creation (see figure 3), and argues that if people are expected to stay engaged they need to be at the top of the pyramid, at least some of the time. For the purposes of this research anything that is not included in these three levels of co creation as put forth by Mogstad, is considered not an instance of co creation and will be classified as 'Impersonal/ External Motivation' as per Ryan and Deci's (2000) Self Determinism theory and facilitation of intrinsic motivation and its resulting self determination continuum. 


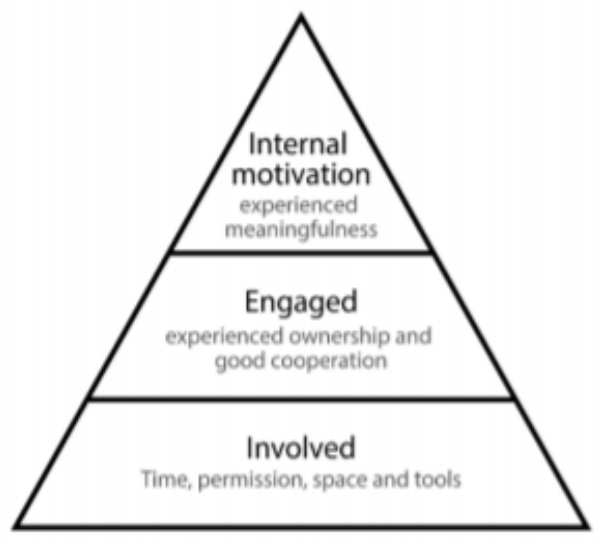

Levels of participation in co-creation

Figure 3: Mogstad (2017) Levels of Participation in Co-Creation

Paskaleva and Cooper (2018), state co production of smart city services is a growing field of study, but what they have suggested is that co-evaluation of the success of delivery is the next logical step in the process. They suggest that in their research, that value is expressed by participants on the onset of the projects, and could be compared to those realized at the end of projects (lbid). This gives smart city projects a baseline, to which success can be assessed and may form an important part of the evaluation processes after the implementation of the various projects in the Smart City Challenge. Using two Smart City Challenge applicant municipalities, Mogstad's (2017) Levels of Participation in Co-Creation will be applied to question number 5 in the application to determine how involved the community was in the process. This will be done based on how the application talks about co-creation, if at all, or how involved citizens are in the process of idea creation. This may range from having citizen groups who are actively involved in the creation of the application, or simply an application that was built by the city, and may simply be inputting the issues and concerns of citizens in their community engagement. 


\subsubsection{Performance Measurement Framework}

Smart City Health projects and interventions can be focused on one main issue, or multiple issues that have complex interconnectedness, and casual relationships to the Canadian health care system and municipal public health agencies (CIHI, 2013).

The Canadian Institute for Health Information (2013) or ClHI released a framework (figure 4) for assessing and reporting performance in the health care system in their report titled A Performance Measurement Framework for the Canadian Health System. The framework is composed of four interrelated quadrants: health system outcomes, social determinants of health, health system outputs and health system inputs and characteristics, in turn four quadrants sits within either the demographic, political, economic and cultural context (CIHI, 2013).

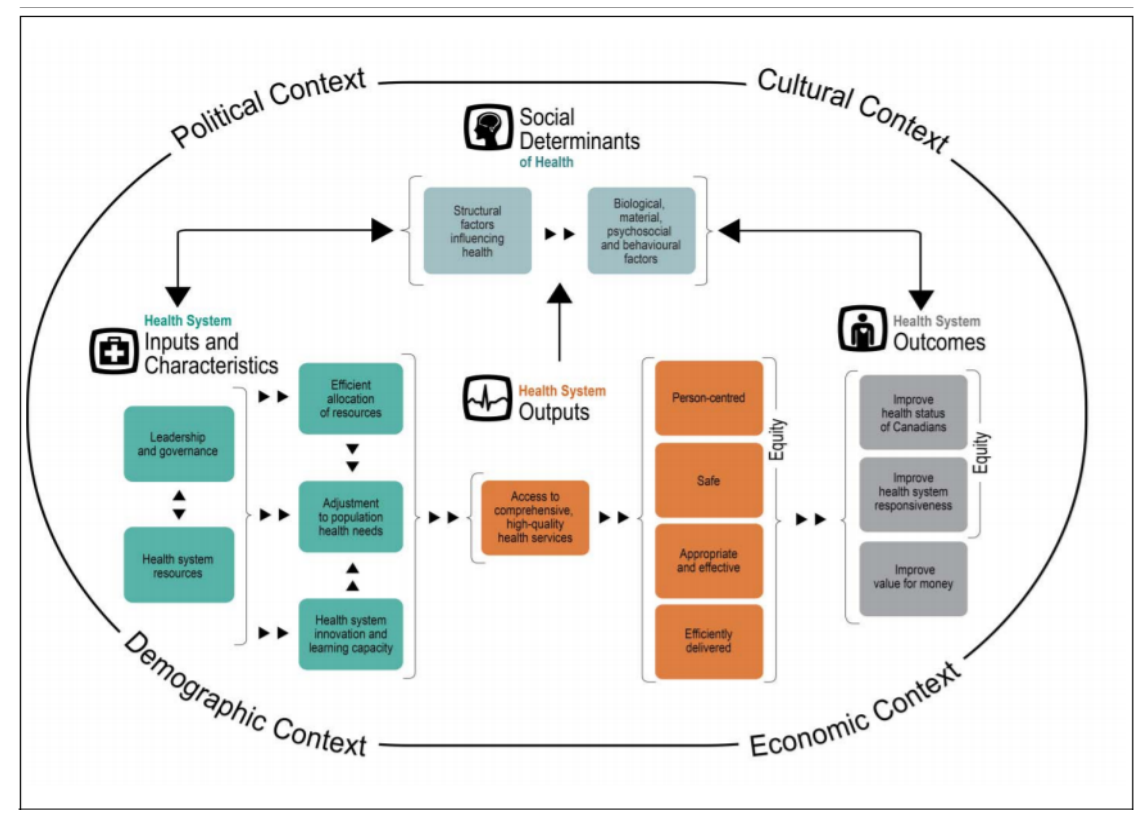

Figure 4: CIHI Performance Measurement Framework for the Canadian Health System 
It is offered as a framework that can be used to manage and improve health system performance, and can support the improvement priorities of Canadian jurisdictions by reflecting the expected causal relationships among sectors of the health system (ibid).

This framework can be used to quantify and analyze the smart city health applicants, to determine which sectors of the health system their proposed intervention has effect. It ties the interventions directly to potential goals and objectives set forth by each jurisdiction, it may also prove to be interesting to see where most of the health interventions were targeted, and if this says anything about the potential of smart city projects and their potency as interventions within the Canadian health care system.

\section{Chapter 3: Method}

The analysis in this research paper is grounded in the literature pertaining to urban health and social determinants, as well as smart city interventions and theories of public service innovation. The literature is derived from diverse sources, including academic literature, government report, NGOs and innovation hubs. The purpose of this research is to discover to what extent is health addressed in the Smart City Challenge, as well as which aspects of health were most targeted in the various Smart City Challenge applicants.

\subsection{Scanning the Applications}

Of the 130 Smart City Challenge applications, 102 were publicly available at the time this research began. These will be reviewed and organized based on themes, with the primary focus being health. Health is defined by the previous literature review. This 
definition will be used in conjunction with the the main proposal themes and the area of focus to organize all the applicants into 3 groups: 'Health Benefits as the Primary Focus', 'Health Benefits as the Secondary Focus', and 'Health Benefits as Tertiary Outcomes'. The criteria of which the applicants will be evaluated is seen in Table 1 below. If the main proposal is includes health as its main theme, it is put into the 'Health Benefits as Primary Focus' category. If in the sub-areas of focus of other applications, there are themes from the 'Primary Focus' criteria but not listed as the main proposal theme, it is placed into the 'Secondary Focus' category. The 'Tertiary Outcomes' category consists of applications that do not explicitly state health as a focus, but intend to improve facets related to the improvement of health and quality of life.

\section{Table 1 Levels of Health Outcome}

\begin{tabular}{|l|l|}
\hline Level of Health Outcome & $\begin{array}{l}\text { Main Proposal Themes and Areas of } \\
\text { Focus }\end{array}$ \\
\hline Health Benefits as Primary Focus & $\begin{array}{l}\text { 'Health', 'Health Care', 'Life Expectancy', } \\
\text { 'Access to Services', 'Mental Health', } \\
\text { 'Isolation', 'Seniors Care', 'Food Security', }\end{array}$ \\
\hline Health Benefits as Secondary Focus & $\begin{array}{l}\text { 'Mobility', 'Transportation', 'Environment', } \\
\text { 'Traffic Safety', 'Green', 'Economy of } \\
\text { Food Production', 'Wellbeing' }\end{array}$ \\
\hline Health Benefits as Tertiary Outcomes & $\begin{array}{l}\text { 'Education', 'Quality of Life', 'Crime } \\
\text { Prevention', Security, 'Accessibility', } \\
\text { 'Inclusiveness' }\end{array}$ \\
\hline
\end{tabular}

The applicants will also be analyzed and grouped into themes of either upstream interventions such as social determinants, or downstream interventions such as chronic disease management or health system reforms. These themes will be identified as through thematic networks analysis, which requires coding the applications and abstracting the themes. The networks are then constructed based on the identified 
themes, and putting them into similar and coherent groupings. Finally, the magnitude into which the applications fit into these themes will be pertinent to understanding how health is addressed in the Smart Cities Challenge

\subsection{Analyzing the Finalists}

The finalists which were identified in the 'Health Benefits as Primary Outcome' category will be analyzed more in depth based on critiques of smart city interventions and technologies. The applications will be analyzed through various lenses such as: the levels of participation in co-creation, the performance measurement framework, and whether or not they address the main critiques of smart city technology (see Table 2). For the 'Levels of Participation in Co-creation question number 5 will be analyzed, "Please describe how your community residents have shaped your Challenge Statement. Describe your plans for continuing to engage and involve them in your final proposal". It should be noted that the analysis of engagement is based solely on selfreporting from the challenge applications, the public was not engaged nor asked about how they felt were engaged.

Table 2: The analysis, frameworks and critiques of which applications will be analyzed

\begin{tabular}{|l|l|}
\hline Analysis/ Framework & Description \\
\hline Main Theme(s) Identified & \\
\hline $\begin{array}{l}\text { Level of Participation (Co Creation } \\
\text { Achieved) }\end{array}$ & $\begin{array}{l}\text { None (Very Low) to Internal Motivation } \\
\text { (High Level) }\end{array}$ \\
\hline CIHI Performance Measurement & Sector Addressed \\
\hline Privacy & Are there measures to protect users? \\
\hline Data Ownership & $\begin{array}{l}\text { Who will own/manage the health data } \\
\text { (if applicable Indigenous Sovereignty) }\end{array}$ \\
\hline
\end{tabular}




\section{Chapter 4: Evidence and Findings}

\subsection{Who is Talking about Health?}

The Smart City Challenge put out by Infrastructure Canada, drew a lot of interest from municipalities, groups of municipalities and various indigenous Nations for a total of 130 eligible applications, of which about $13 \%$ of them identified their projects under the 'Healthy Living and Recreation' theme (Infrastructure Canada, 2018). The theme of 'Healthy Living and Recreation' is rather broad and excludes many facets of health that were nested in other categories such as aspects of 'Environmental Quality' and 'Social Inclusion'. Realistically, all of the Smart City Challenge application will have some effect on Health; For this reason, applications were analyzed based on the degrees of which health benefits were sought after as outcomes to their Smart City interventions.

In the Smart City Challenge, applications were categorized into six separate and distinct focus areas: Economic Opportunity, Empowerment and Inclusion, Safety and Security, Mobility, Healthy Living and Recreation, and Environmental Quality. They were based on question 18 of the application that was not made publically available in Section 3. It made the applicants self-identify their project into the six distinct focus areas, of which the applicants were allowed to choose up to two of the focus areas. 


\begin{tabular}{|l|l|}
\hline Smart City Challenge Definition of Health & $\begin{array}{l}\text { Definition of Health as Defined by This } \\
\text { Research }\end{array}$ \\
\hline $\begin{array}{l}\text { "Residents are able to live an active and } \\
\text { healthy life. Examples of outcomes in this } \\
\text { area could include: increased access to } \\
\text { recreational programming; availability of } \\
\text { remote health services; reduction in } \\
\text { adverse health outcomes, etc." (Impact } \\
\text { Canada, 2018). }\end{array}$ & $\begin{array}{l}\text { Citizen health can be characterized by the } \\
\text { quality of their lifestyle (diet, physical } \\
\text { (social capital, and networks), their } \\
\text { activities (living, playing learning, moving, } \\
\text { shopping, and working), their built } \\
\text { environment buildings, places, streets, } \\
\text { and routes), and their natural environment } \\
\text { (natural habitats, trees, air, water, land, } \\
\text { soils). It also includes the mental and } \\
\text { physical wellbeing of residents, beyond } \\
\text { the simple absence of ailment. }\end{array}$ \\
\hline
\end{tabular}

The widening of the definition of health, was in relation to the acknowledged and informed interconnectedness of citizen health, on a variety of other factors including socioeconomic indicators, food security, mental health, isolation, and environment (See Table 3). This overlaps with many of the distinct focus areas as defined by Infrastructure Canada, in particular: Environmental Quality, Economic Opportunity and Empowerment and Inclusion.

For the purposes of this research the applications were analyzed and grouped based on their areas of focus and themes into the three categories, 'Health Benefits as Primary Focus', 'Health Benefits as Secondary Focus' and, 'Health Benefits as Tertiary Outcomes'. As seen in Table 4 below most applications fell within the 'Tertiary Outcomes' category $55.4 \%$, followed by the 'Primary Focus' category at $24.8 \%$, and 
$19.8 \%$ for the 'Secondary Focus' category. The 'Primary Focus' is slightly higher than the original $13 \%$ from the Infrastructure Canada Challenge Dashboard, indicative of the widened criteria of health. This indicates that the majority of applicants were not directly health focused, but instead focused on different aspects of wellbeing. However, that more applications had health benefits as their primary focus than previously identified.

Table 4: Applications and Levels of Health Outcome categories

\begin{tabular}{|l|l|}
\hline Level of Health Outcome (First Phase) & Percentage of Applicants within Category \\
\hline Health Benefits as Primary Focus & $24.8 \%(25)$ \\
\hline Health Benefits as Secondary Focus & $19.8 \%(20)$ \\
\hline Health Benefits as Tertiary Outcomes & $55.4 \%(57)$ \\
\hline
\end{tabular}

The same analysis was done again for the 20 finalists (see Table 5 and Table 6), to demonstrate how health related Smart City applications performed in the challenge. The results proved to be very different from the original analysis. Those in the 'Primary Focus' category made of the majority of the finalists at $50 \%$. Followed by 'Tertiary Outcomes' at $30 \%$ and 'Secondary Focus' at $20 \%$. This shows that health focused applications performed much better than their non-health focused counterparts, to ultimately ended up as finalists.

Table 5: Finalist applications and which Level of Health outcome they were classified as

\begin{tabular}{|l|l|l|}
\hline Finalist Municipality & $\begin{array}{l}\text { Prize } \\
\text { Category }\end{array}$ & Health Detail \\
\hline Edmonton & $50 \mathrm{~m}$ & Primary- Health, Inequality \\
\hline City of Montreal & $50 \mathrm{~m}$ & Primary- Food, Mobility, Access (Inequality) \\
\hline Waterloo Region & $50 \mathrm{~m}$ & Primary- Mental Health, Youth, Social Determinants \\
\hline Ville de Quebec & $50 \mathrm{~m}$ & Primary- Health, Inequality \\
\hline
\end{tabular}




\begin{tabular}{|c|c|c|}
\hline Guelph and Wellington County & $10 \mathrm{~m}$ & Primary- Health, Food, Waste, Social Determinants \\
\hline $\begin{array}{l}\text { Town of the Pas, Opaskwayak } \\
\text { Cree Nation, Rural Municipality } \\
\text { of Kelsey }\end{array}$ & $10 \mathrm{~m}$ & Primary- Health, Food, Social Determinants \\
\hline Airdrie and Area & $10 \mathrm{~m}$ & $\begin{array}{l}\text { Primary- Health, Health Care [Access to], Social } \\
\text { Determinants }\end{array}$ \\
\hline $\begin{array}{l}\text { Nunavut Association of } \\
\text { Municipalities }\end{array}$ & $10 \mathrm{~m}$ & Primary- Mental Health, Youth, Social Determinants \\
\hline Ville de Côte Saint-Luc & $10 \mathrm{~m}$ & Primary- Health, Seniors, Isolation, Environment \\
\hline Mohawk Council of Akwesasne & $5 m$ & Primary- Health, Access (Inequality) \\
\hline Vancouver and Surrey & $50 \mathrm{~m}$ & $\begin{array}{l}\text { Secondary-Transportation, Mobility, Environment, } \\
\text { Safety }\end{array}$ \\
\hline Greater Victoria & $10 \mathrm{~m}$ & $\begin{array}{l}\text { Secondary- Mobility, Transportation Affordable, } \\
\text { Wellbeing, }\end{array}$ \\
\hline $\begin{array}{l}\text { Parkland County, Brazeau } \\
\text { County, Lac Ste Anne County, } \\
\text { Yellowhead County }\end{array}$ & $10 \mathrm{~m}$ & $\begin{array}{l}\text { Secondary- Internet Access, Safety, Crime, } \\
\text { Education }\end{array}$ \\
\hline Bridgewater & $5 m$ & Secondary- Energy, Transportation, Mobility \\
\hline $\begin{array}{l}\text { City of Fredericton and Saint } \\
\text { Mary's First Nation }\end{array}$ & $10 \mathrm{~m}$ & Tertiary - Accessibility, Inclusion, Quality of Life \\
\hline Richmond & $10 \mathrm{~m}$ & Tertiary - Safety, Mobility, Transportation \\
\hline Saskatoon & $10 \mathrm{~m}$ & $\begin{array}{l}\text { Tertiary- Youth, Crime prevention, Economic Dev, } \\
\text { Education (Social Determinant) }\end{array}$ \\
\hline $\begin{array}{l}\text { Biigtigong Nishnaabeg (Pic } \\
\text { River First Nation) }\end{array}$ & $5 \mathrm{~m}$ & Tertiary- Education, Language, Youth \\
\hline Cree Nation of Eastmain & $5 m$ & Tertiary- Housing, Environment, Energy \\
\hline Yellowknife & $5 m$ & Tertiary- Sustainability, Environment, Energy \\
\hline
\end{tabular}

Those in the 'Primary Focus' category also had a much higher proportion of applicants in the $\$ 50$ Million prize category, making up $80 \%$ of those in the category. As well, they made up $\$ 50 \%$ of those in the 10 Million prize category. Also of note, Indigenous Communities made up 30\% of applicants in the 'Primary Focus' category, and $30 \%$ of all finalists in the Smart City Challenge, in comparison to making up $15.4 \%$ 
of all Challenge Applications, but none were within the $\$ 50$ million prize category. This analysis is indicative of the importance of health in Canadian municipalities due to the fact that a relatively large number of applications either directly seek to have positive health impacts or have secondary health benefits associated to their smart city initiatives.

Table 6: Finalist Applications and Levels of Health Outcome categories

\begin{tabular}{|l|l|}
\hline Level of Health Outcome Finalists & Percentage of Applicants within Category \\
\hline Health Benefits as Primary Focus & $50 \%(10)$ \\
\hline Health Benefits as Secondary Focus & $20 \%(4)$ \\
\hline Health Benefits as Tertiary Outcomes & $30 \%(6)$ \\
\hline
\end{tabular}

\subsection{What Health Issues do the Finalists Hope to Address Using Smart City Tech?}

Previous work on the Smart City Challenge applications included identifying the the main focus of each of the applications. In total there were 25 main proposal themes in the 'Health Benefits as Primary Focus', these were then grouped together by overarching themes and by similarity and reduced to 8 main themes. 'Health and Overall Wellbeing' is includes the broad themes of health, wellbeing, prevention and quality of life as mentioned by the application. The theme of 'Mental Health' was combined with suicide prevention. The theme of environment consists of the themes of waste, and safety. The Theme 'Social determinants' consists of, education, job skills training, graduation rates and employment. Finally the theme 'Inequality/Inequity' consists of access to services, inequality and social inequality. It is important to note 
that one application may have talked about several themes, therefore would be counted in more than one main theme.

Table 7: Themes of Health in the Primary Health Benefits category

\begin{tabular}{|l|l|l|}
\hline Main Themes & Occurrence & $\%$ \\
\hline Health and Overall Wellbeing & 18 & 28.6 \\
\hline Mental Health & 5 & 7.9 \\
\hline Food & 5 & 7.9 \\
\hline Environment & 5 & 7.9 \\
\hline Social Determinants & 17 & 27 \\
\hline Youth & 7 & 11.1 \\
\hline Senior & 3 & 4.8 \\
\hline Inequality/lnequity & 3 & 4.8 \\
\hline
\end{tabular}

Overall the results show (Table 7 above) that the main theme of 'Health and Overall Wellbeing' was the most prominent theme mentioned in all of the applicants in the 'Primary Focus' level of health outcome which had an occurrence of 18 , making up $28.6 \%$ of the main themes mentioned. Following closely in second is 'Social Determinants' which had an occurrence of 18 and made up $27 \%$ of the main themes mentioned. Youth came in third with an occurrence of 7 and made up $11.1 \%$ of the main themes mentioned. The themes of 'Mental Health', 'Food', and 'Environment' all the occurrences of 5 making each making up $7.9 \%$ of the main themes mentioned. Finally, 'Senior' and 'Inequality/Inequity' both make up $4.8 \%$ of the main themes mentioned.

Table 8: Themes of Health in the Finalist Primary applications

\begin{tabular}{|l|l|l|}
\hline Main Themes & Municipalities & $\%$ \\
\hline Health and Overall Wellbeing & Edmonton, Airdrie and Area, & 19.0 \\
\hline
\end{tabular}




\begin{tabular}{|l|l|l|}
\hline & $\begin{array}{l}\text { Mohawk Council of Akwesasne, } \\
\text { Ville De Quebec (4) }\end{array}$ & \\
\hline Mental Health & $\begin{array}{l}\text { Nunavut Association of } \\
\text { Municipalities, Waterloo Region } \\
(2)\end{array}$ & 9.5 \\
\hline Food & $\begin{array}{l}\text { Guelph and Wellington County, } \\
\text { Ville de Quebec (2) }\end{array}$ & 9.5 \\
\hline Environment & $\begin{array}{l}\text { Guelph and Wellington County } \\
(1)\end{array}$ & 4.8 \\
\hline Social Determinants & $\begin{array}{l}\text { Edmonton, Airdrie and Area, } \\
\text { Nunavut Association of } \\
\text { Municipalities (5) }\end{array}$ & 23.8 \\
\hline Youth & Waterloo Region (1) & 4.8 \\
\hline Senior & $\begin{array}{l}\text { Ville de Côte Saint-Luc, } \\
\text { Montreal (2) }\end{array}$ & 9.5 \\
\hline Inequality/Inequity & $\begin{array}{l}\text { Airdrie and Area, Mohawk } \\
\text { Council of Akwesasne, Ville de } \\
\text { Quebec, Montreal (4) }\end{array}$ & 19.0 \\
\hline
\end{tabular}

The results from analyzing the main themes from the finalists from the 'Primary Outcome' category do not vary drastically from the first phase of the Challenge, however there are some differences (see Table 8). The main theme of 'Social Determinants' was the most prominent theme at $23.8 \%$, followed closely by 'Health and Overall Wellbeing' at $19.0 \%$. The theme of 'Inequality/Inequity' was tied at $19.0 \%$ followed by 'Mental Health' and Food at $9.5 \%$ each. It seems that the themes of Health and Wellbeing and Social Determinants make up the majority of applicants both in the first phase of the challenge, and during the finalist portion. Indicating, a favouring of interventions aimed at more broad and encompassing themes rather than specific themes.

\subsection{The Finalists}


Two case studies were chosen to analyze in depth in order to see how they chose to address health concerns, including major themes, using the $\mathrm{ClHI}$ framework to determine where their intervention takes place in the Canadian health system, as well as how well they addressed or failed to address the main critiques of smart city technologies. The two case studies that were chosen for further analysis were the Edmonton application and the Mohawk Council of Akwesasne. The Edmonton application was chosen based on the fact that it was within the 'Primary' category and was in the $\$ 50$ Million category as well as their partnership with Telus and the Alberta Blue Cross. The Mohawk Council of Akwesasne's application was chosen for further analysis, to see how indigenous communities deal with data sovereignty, as well as plan to govern their health data especially with private sector partnerships.

\subsubsection{The City of Edmonton}

\section{Main Themes}

The City of Edmonton's Smart City Challenge application was very health focused, and plans to create a 'Health Data Repository' that will allow residents to access health supports and provides them with tools to improve their personal health. This application touches on main themes of 'Health and Overall Wellbeing', 'Social Determinants' and 'Inequity/Inequality'. These three themes are the most prominent main themes of all the health based applications, and are the most encompassing. Other sub-themes identified are: 'Mental Health', 'Isolation', 'Seniors', 'Newcomers', 'Integration', and 'Connectivity'. The application intends to create a 'Healthy City Ecosystem' . 
The ecosystem intends to base itself on three current baseline measures: the City of Edmonton Citizen Satisfaction Survey, Loneliness: PEGASIS survey of Edmontonians over 55, and the Canadian Community Health Survey. Furthermore, the City intends to engage with stakeholders who have already collected personal data, and harvest data from wearables. The database will then be accessible and shared by the variety of stakeholders involved. The results will be the aforementioned Heath Repository, as well as a digital tool that can be accessed by computer or kiosk to help guide residents to relevant programming and services.

\subsubsection{Edmonton: Co Creation Analysis}

Utilizing the Levels of Participation in Co creation by Mogstad (2017), the City of Edmonton's application was analyzed, particularly Question 5 which was concerned with resident engagement. The application has stated, 'Edmonton is a community in which residents are engaged and lead the development of Edmonton's long term strategic priorities" (City of Edmonton Smart City Challenge Application, 2018). As well, the application has stated that, The City launched the Program- dedicating staff at the leadership level to advance innovation, digital enablement and partnership-building (ibid). Moreover, the application states that the community should determine the approach, and engagement was then intensified by city stakeholders.

Based on these findings, and through analysis of question 5 of the City of Edmonton's smart city challenge application was placed on the first level of Mogstad's Levels of Participation in Co creation pyramid, which is 'Involved'. The application is placed at the first and lowest level based on Mogstad's definition that participants have been involved in the co-creation process, primarily through "simple reporting problems, 
and hoping they get resolved" (Mogstad, 2017). Furthermore, the 'Involved' stage simply lists that "time, permission, space and tools" were provided at this level. In order for more meaningful engagement to occur, Mogstad suggests that participants must spend at least some time at the top of this pyramid in order to feel like they have ownership of the project.

As it stands now in the Edmonton application, the city seems to be mainly in control of the project, and seem to be the sole designers of the application and engagement process. Mogstad has stated early participation in the process can create ownership in the project and providing autonomy as an important aspect of progressing up the pyramid. It is important the city does not solely dictate the process, and allows citizens to not only guide the outcomes of their Smart City Challenge, but to co-create the engagement, the tools and the data necessary for the project. It should be noted however, the City of Edmonton has still amassed a wealth of insight from effective public consultation.

\subsubsection{CIHI New Health System Performance Measurement Framework Analysis}

Using the CIHI's "New Health System Performance Measurement Framework" analysis the City of Edmonton's Smart City Challenge application is assessed to determine performance measurement within the four quadrants. In particular, Question Four of the Smart City Challenge application was analyzed as it is concerned with expected outcomes. Keywords that were used to identify the location of the outcomes in the framework were: 'Social Determinants of Health', 'Prevention', and 'Responsive'. Furthermore, the application states “The City of Edmonton's proactive approach proposes to improve people's health by addressing the root causes of health issues, 
rather than treating the symptoms". (City of Edmonton, 2018). These keywords were selected due to their indication to the time and place of the healthcare intervention, these solutions can be deemed upstream and proactive.

Given the evidence amassed in the the keywords scan, the City of Edmonton's application makes advances within two quadrants: the 'Health System Inputs and Characteristics' and 'Social Determinants of Health'. The Health System Inputs and Characteristics quadrant are considered "prerequisites of health system performance" (CIHI 2013). The aspects within this quadrant that are directly mentioned in the Edmonton application are efficient health system resource allocation that is proactive, and innovation based on an ecosystem approach that can adjust the capacity of the health system to current user needs. The application addresses the 'Social

Determinants of Health' quadrant by focusing primarily on social determinants of health as both baseline and measurements of success, although the determinants they chose are not completely mentioned in the application.

\subsubsection{Addressing Main Critiques}

The City of Edmonton application was also analyzed to see whether or not it addresses the main critiques to smart city technology. Doing so, will provide the basis for recommendations and feedback to build and create more robust smart city infrastructure, and requirements for future Smart City Challenge applications.

Table 9: City of Edmonton and Smart City Critiques

\begin{tabular}{|l|l|}
\hline Main Critique & Was it Addressed? \\
\hline Privacy and Consent & $\begin{array}{l}\text { Yes, in partnership with Alberta's Office of } \\
\text { the Information and Privacy } \\
\text { Commissioner }\end{array}$ \\
\hline
\end{tabular}




\begin{tabular}{|l|l|}
\hline Indigenous Data Sovereignty & Not Addressed \\
\hline Data Discrimination & Not Addressed \\
\hline Data Ownership and Stewardship & $\begin{array}{l}\text { Ownership not addressed, but open data } \\
\text { sharing amongst private and public } \\
\text { partners mentioned. }\end{array}$ \\
\hline
\end{tabular}

Of the four main critiques only one was explicitly mentioned in the smart city application (see Table 9). The issue of privacy and consent was addressed in the city's application by identifying a partnership with Alberta's Office of the Information and Privacy Commissioner, as well as stressing that data will be anonymized and aggregated multiple times throughout the proposal, however no clear plan has been stated. As to how the proposal intends to deal with issues of data discrimination, this is rather unclear other than the aforementioned privacy measures. This is concerning considering the private partnerships are with a health insurance provider, and one of Canada's largest telecommunication companies.

Although not an indigenous community the issue of Indigenous data sovereignty was not addressed in the proposal, it should be noted however that indigenous community members were included as a primary group for engagement and consultation. As for the issue of data ownership and stewardship, the City seems to have placed itself as the main facilitator of the data sharing aspect of the project, it has marketed this proposal as an attempt to coordinate disparate and separate datasets that already exist and open sharing of the completed health repository. This indicates that data ownership is spread amongst many stakeholders, and it may prove difficult to assure privacy and full stewardship when the municipality may need to divulge information in order to gain access to the disparate data sets. Third Party privacy 
arrangements will be necessary in order to ensure privacy among stakeholders and citizens.

\subsubsection{Mohawk Council of Akwesasne Main Themes}

The Mohawk Council of Akwesasne 's (MCA) Smart City Challenge proposal also fell within the 'Primary' group, and presented itself as a health oriented projects whose main goal is to create a 'Health Optimizing Framework'. The main themes of this proposal are: 'Health and Overall Wellbeing', 'Inequity/Inequality' and 'Food' as they focus on tracking cases of diabetes, providing a user interface to direct people to services and other interventions to prevent future diagnosis, and an online food delivery service as well as a smart greenhouse. Other sub-themes identified are: 'Social Determinants', 'Environment', and 'Mental Health'.

They have partnered with zu, a digital products firm from Saskatoon to follow a design thinking process to create what they are calling a 'Health Optimizing Framework' which is the combination of record keeping, data aggregation and reporting, educational information and other sub-applications (Mohawk Council of Akwesasne, 2018). It will take form in a mobile application for residents, which they can track their own health and be directed to relevant services. The data collected will be used by the MCA's Department of Health and Diabetes Management Team to track diabetes cases, as well as to give information to doctors when patients have to access the fragmented interprovincial health care system. This is seen as a combination of modern medicine, digital tools and traditional holistic approaches. 


\subsubsection{Co Creation Analysis}

Utilizing the Levels of Participation in Co creation by Mogstad (2017) MCA's, application was analyzed, particularly Question 5 which was concerned with resident engagement. A few key themes from the question response were used to determine where they could be placed on the Co-creation pyramid.

The proposal stated that they had conducted a Community Health Program Open House Survey in 2017 as well as a SMART Akwesasne survey to determine what their major health concerns were, satisfaction of service, and to rank areas of life were most important (Mohawk Council of Akwesasne, 2018). Furthermore the Council also held two design thinking workshops with stakeholders to determine the focus of the challenge projects, and is considered user-centred design. The proposal also states that the design thinking methodology will also be used for the continuous testing at both the development state and the implementation stage (Mohawk Council of Akwesasne, 2018).

Based on these finding the Mohawk Council of Akwesasne's proposal, more specifically their answer to question 5 of the Canadian Smart Cities Challenge application, the proposal was placed on the third and top level "Internal Motivation". The criteria for achieving "Internal Motivation" is that participants are true co-creators, in that they experience autonomy and meaningful as well as impactful work (Mogstad, 2017). By following a design thinking process, the users are ultimately thought of at the very beginning, and they are given control of the project. Mogstad (2017) states that users need to only be at the top for most of the project, in order to benefit from the positive effects of co-creation. It is important that this design thinking process remains iterative, 
and that users truly are immersed in the implementation and testing process to fully benefit from co-creation.

\subsubsection{CIHI Framework Analysis}

Using the ClHI's "New Health System Performance Measurement Framework" analysis the MCA's Smart City Challenge application is assessed to determine performance measurement within the four quadrants. In particular, Question Four of the Smart City Challenge application was analyzed as it is concerned with expected outcomes. Keywords that were used to identify the location of the outcomes in the framework were: 'Diabetes', 'Reduce Number of New Cases', 'Lifestyle Factors' and 'Education' (Mohawk Council of Akwesasne, 2018). The proposal states, " The main goal of this Smart Cities Challenge will be to reduce the number of new cases of diabetes per year moving forward...", as well, "We will improve diets, increase regular physical activity and create better access to healthcare... to decrease risk factors" (Mohawk Council of Akwesasne, 2018).

Given the evidence amassed in the the keywords scan, the MCA's application makes advances within two quadrants: 'Social Determinants of Health', and 'Health System Outcomes'. The proposal focuses on the 'Social Determinants of Health' quadrant by focusing on improving access to education, healthy sources of food, and encouraging more active lifestyles, this is referred to risk reduction in the proposal (Mohawk Council of Akwesasne, 2018).

Furthermore, the project targets the 'Health Systems Outcomes' quadrant by improving access to high comprehensive, high quality health services through the focus on building a framework that will digitize patient data and diagnostics thereby creating a 
more efficient and person-centred health care process. As well, the Health Optimizing Framework intends to create an educational platform that will guide users to information and services based on health requirements therefore increasing the accessibility to health providers and equipping citizens with knowledge.

\subsubsection{Addressing Main Critiques}

The MCA application was also analyzed to see whether or not it addresses the main critiques to smart city technology.

\section{Table 10: MCA and Smart City Critiques}

\begin{tabular}{|l|l|}
\hline Main Critique & Was it Addressed? \\
\hline Privacy and Consent & $\begin{array}{l}\text { Yes } \\
\text { "Privacy measures preserving data anonymity } \\
\text { and sharing will be scoped into the planning } \\
\text { process " pp 8 (Mohawk Council of } \\
\text { Akwesasne, 2018) }\end{array}$ \\
\hline Indigenous Data Sovereignty & $\begin{array}{l}\text { Yes, not explicitly addressed, although it is a } \\
\text { completely community-based undertaking }\end{array}$ \\
\hline Data Discrimination & Not Addressed \\
\hline Data Ownership and Stewardship & $\begin{array}{l}\text { Ownership not explicitly addressed although } \\
\text { it is a completely community-based } \\
\text { undertaking. } \\
\text { open data sharing amongst community } \\
\text { members (summaries) } \\
\text { Private partner 'zu' seems to be a } \\
\text { consulting partner to facilitate } \\
\text { engagement and platform building. }\end{array}$ \\
\hline
\end{tabular}

The proposal was analyzed through the various main critiques of smart city technologies (see Table 10). Of the four critiques identified only one was explicitly mentioned, two were inferentially addressed and one was not addressed. Privacy was addressed multiple times in the proposal, through keywords like: 'anonymity', 'privacy', 
and 'aggregate' (Mohawk Council of Akwesasne, 2018). There was no explicit plan for developing a privacy and consent plan, however the proposal mentions, "Privacy measures preserving data anonymity and sharing will be scoped into the planning process". Being more clear as the process progresses will be important to maintain transparency.

Indigenous data sovereignty is an important issue to address, given this proposal belongs to an indigenous community. The issue is not explicitly mentioned in the proposal, however through analysis of the application, the initial proposal was launched by the MCA itself and given approval by the Grand Chief. The only outside partner involved in the process is zu, who is involved in facilitating a design thinking process, and building the online platform. It appears from the surface that the data is completely owned by MCA, and they have full control and stewardship of it.

Although, stewardship and ownership are also not addressed there is no indication that there will be an outside private partner with whom data will be shared with. Finally, the critique of data discrimination was not addressed but should be considered if and when MCA decides to make further partnerships in different sectors, or make data available for external analysis. There ought to be the creation of a robust framework or set of regulations around allowing third party vendors access to their information, one that keeps in mind OCAP data protocols and the other indigenous data stewardship recommendations by the British Columbia First Nations Data Governance Initiative. 


\section{Chapter 5 Conclusions and Recommendations}

\subsection{Limitations}

Given the nature of the proposal guidelines, this analysis comes with limitations that need to be addressed in order for the analysis to be considered a fair interpretation. The outlined limitations may also prove to be areas that can improve when the Smart Cities Challenge has its second iteration, so that applicants can put forth more robust and sound proposals.

\subsubsection{Word count for questions}

Certain questions where applicants needed to express objectives, methodologies and background research has very specific word counts. For instance Question 8 requires the applicants to both address community readiness and to describe organization structures put in place, all while also identifying organizational weaknesses with a limiting word count of 1000 words but given a weight of 10/100 (Impact Canada, 2017). Question 5 requires applicants to describe their community engagement strategies, but gives 1500 words and a weight of 15/100 (ibid).

These two questions in particular had the opportunity to allow applicant communities to describe in depth privacy strategies, data governance strategies, as well as to describe efforts of co-creation in the innovation process. The concise word limit may have pressured applicants to omit many of the answers to the main critiques both because they were not required answers, but also because there may have not been enough room for discussion.

\subsubsection{Sample Case Studies}

The case studies chosen may not have provided a broad enough sample of applicants of the smart cities challenge. Due to the scope of this research and analysis, 
the two provided a sufficient amount of insight into two diverse applicant groups. The findings of these sample case studies should not be interpreted as exhaustive and further research should occur, if the scope of research is extended beyond this analysis.

\subsubsection{Round One of Proposals}

A third limitation is that these are only the first round of the proposals, this round of proposals were not as in depth as necessary to produce a full analysis on the submissions. Further analysis would need to be done to ensure the proposals did go more in depth into many of the criticisms of smart city technologies, and data security and stewardship. This research was done before the final submissions were submitted to Infrastructure Canada, and therefore had to rely on the first round of proposals. A future recommendation is that an analysis is done both on the finalist submissions, as well as the winners of the challenge.

\subsection{Recommendations for Future Iterations}

\subsubsection{Greater Protections for Individual Privacy}

Responding to major smart city criticism from academics and industry professionals such as O'Doherty et al. (2016), Kitchin (2016), Bannerman and Orsach (2019) and Wylie (2018) there needs to be greater protections for individual privacy. In the digital age where intergovernmental interference, hacking and data breaches are becoming the new global threat simply stating promises of anonymity, and data aggregation is not enough. The Smart City Challenge application requirements actually require no privacy or security plans from applicants, nor whether or not they intend to be the stewards of data. 
Given the extremely sensitive nature of health data and the harvesting of personal information, there needs to be a component where applicant cities either state they have begun to consult their respective privacy commissioner, or created a partnership with a digital security consultancy. Furthermore, there needs to be a more concrete plan in place before the collection of citizen data. This may include a requirement for appending an example of a consent to participate sheet, consulting the Canadian Research Ethics Board, including and making explicit and public a data ownership clause in partnership agreements, as well as drafting a data security plan. Hopefully, the construction of a strong and robust privacy plan or civic data trust comes with the finalist submissions.

Sidewalk Toronto, the joint collaboration between Google's Sidewalk Labs and Waterfront Toronto, have created a responsible data use framework which seeks to outline how all data will be governed. The four main areas of responsible data use are: privacy, stewardship, access to data and data security (Sidewalk Toronto, 2018). Furthermore, Sidewalk Toronto believes data should only be collected for beneficial purposes, they stress transparency and openness, proactive engagement, community trust and put people first (ibid). An example of a data solution that has come out of Sidewalk Toronto is the civic data trust. The civic data trust would be a third party independent body that is primarily concerned with the stewardship of all data collected in the physical environment relating to the project (Sidewalk Labs, 2018). This data is classified as "Urban Data", and would be guarded and distributed through the Responsible Data Use Guidelines, and the civic data trust (ibid). 
The creation of civic data trusts, although a relatively new idea, is something that needs to be considered when collecting sensitive data, that will either be used for proprietary purposes or published publicly. The stewardship and collection of large and sensitive data sets, may prove too complex for municipalities to manage without the help of a third party body, or larger data protection agency. These rules of course will not in lieu of the current legislation regarding privacy, but should enhance and guide it to make it applicable in the new and dynamic ways smart city technology will dictate (ibid). Infrastructure Canada should look into new and dynamic ways to support communities, which may not have the capacity to manage the massive amounts of citizen data themselves. Perhaps, this may include a body that is responsible for overseeing big data.

\subsubsection{Greater Resident engagement//nvolvement}

Impact Canada's (2017) guide for applicants states engagement should be "meaningful" and that there should be plans to sustain engagement throughout the process. Having a definition of meaningful, or pursuing more innovative engagement streams such as co-creation may prove to yield more impactful results. Perhaps the creation of a citizen's advisory council from the very start should be mandatory, so that a design-thinking process is maintained throughout the competition and into implementation and prototyping.

As Mogstad (2017) states, when participants have a stake in the creation and ideation from the very beginning, they experience autonomy and ownership of the idea and therefore become more personally invested in seeing the project be successful. Applicant communities should refrain from ceremonious or symbolic engagement 
processes that only seek to allow residents to feed in complaints and problems in hopes they get resolved. As well, applicants should refrain approach the community with a finished product, plan or idea, that was made without their consultation and expect full meaningful participation. Given the importance and necessary component of citizen health data in Smart Health interventions, citizens should have a chance to be stewards of their own data.

\subsubsection{Having Health and Wellbeing as Core Tenets of a Smart City Challenge}

All of the Smart City Challenge applications intend to improve the quality of life of citizens living in the respective community or communities. This competition ultimately achieved a goal of inciting innovation and pushing for new forms of dynamic governance and citizen connection. While innovation requires a rather open ended procurements in order to think outside of the box, there seems to be a heavy focus on communities aiming to increase health and wellbeing of citizens and target groups. Future iterations of the Smart City Challenge may benefit from targeted themes such as: urban health, health inequities, wellbeing, active transportation etc.

Doing so may create a greater diversity of innovation in one particular topic, and may yield more groundbreaking results. For example the Defense Advanced Research Projects Agency (DARPA) holds competitions, based on refined themes such as autonomous vehicles and robots, and artificial intelligence that have created large knowledge banks and have made considerable progresses in those respective fields. As well, the US Department of Transportation (2017) held their own Smart Cities Challenge, that resulted in the publication of a report on findings and recommendations for the implementation and future of smart transportation in American cities. 


\subsubsection{Greater Protections for Indigenous Data and Communities}

The OCAP data protocols lay out the groundwork for nation to nation relations as it relates to research and data collection. Indigenous communities that enter into the Smart City Challenge, should be provided further support to ensure full ownership and full stewardship. Indigenous communities should also be prepared to figure out how they will navigate the issues of access and control, as it pertains to third party vendors and private partnerships. Understandably, the Nations will be engaging with private partnerships in order to get their Smart City technologies working and in place, learning how to navigate these relationships will be crucial to the future of indigenous data sovereignty. OCAP provides programs for researchers who are interested in conducting research with an indigenous nation. As well the indigenous communities ought to consult the First Nations Information Governance Centre, or should be a partner with Infrastructure Canada at the beginning of the Challenge, to help communities learn more about how they can protect their sovereignty in the process.

\subsection{Recommendation for Future Practice}

The histories of health and urban planning are intertwined, with the latter finding itself as a profession due to the problems and sanitation issues that accompanied rapid urbanization. The American Planning Association (2016) calls on planners and decision makers to acknowledge the direct relationship between risk of disease and the built environment, the natural environment and infrastructure. Closer to home, the Canadian Institute of Planners (CIP) has launched the Healthy Communities Policy (2018). This policy helps to outline what built form and natural environments best create and 
facilitate health, and it ultimately places the planner as a key player. The CIP, states “...that planners have a responsibility to make decisions and plan in a way that... supports the development of healthy, equitable, and inclusive communities" (2018, pp 5). Some of the key themes planners must keep in mind when planning is social and health equity, meaningful engagement, social and cultural inclusion, acknowledging the effects of determinants of health, use scientific research and available data, and be knowledgeable on policies, frameworks and targets (UN SDG, and New Urban Agenda) (ibid). The policy ends with a call to action, that recognizes that, "all planners have a responsibility to plan and support the development of healthy communities and make decisions according to the principles of healthy community planning" (CIP, 2018, pp 7).

Future practice can find ways to incorporate smart city technologies and outputs into zoning bylaws, secondary plans, official plans, design guidelines. The American Planning Association (2016) provides an Planning Advisory Service Info Packet for planning practitioners to meaningfully incorporate health into everyday planning policy. The CIP also provides a Healthy Communities Practice Guide that provides planners with a great wealth of key resources as it related to health and built environment, and give planners the tool necessary to identify the interconnected nature of health and planning (CIP). Similarly, the OPPI released Planning By Design: A Healthy Communities Handbook (2009), that also charges planners with the task of incorporating health into their planning decisions (OPPI, 2009).

Smart City Challenge applicants who focused on health, attempt to address social determinants and biological determinants of health and a variety of other themes. As well, planners who choose to engage with Smart City Challenge applications that are 
health focused, are well equipped with a large body of knowledge, resources and handbooks to implement health-technology based interventions.

Other recommendations into future practice may include looking further into the concept of Smart Zoning as researched by Arif et al (2015), which consists of, "using technology to specify outputs rather than inputs; using formulas rather than specifications; request, gather, and analyze citizen input on goals and particular zoning decisions... [it] has the potential to provide a more flexible model of zoning, responsive to public needs and demands...". This model combined with health input has the potential to create dynamic zoning policies, that can be responsive to changes in determinants of health.

\subsection{Future Research}

Future research initiatives in the Smart Health field have a wide breadth of directions and topics. First and foremost any future research on smart city technology in Canada, should follow up on the winners of the Smart City Challenge. In particular, analyzing the implementation of health-oriented projects and the effectiveness of the intervention. Looking at the longevity and sustainability of the projects will be important as well to all future work in the smart city, and understanding how cities will upkeep the smart infrastructure over long periods of time. As well, what will happen when the partners decide to leave, are cities well equipped to handle the projects on their own. The creation of a best practices guide for future health-oriented Smart City Challenge applicants, will help to guide future projects as well as to lay the foundational groundwork. 
Another topic of research is using smart city technology to help contain, and end the opioid crisis. Using existing smart health infrastructure to help guide decision makers, and to mobilize resources. As well, creating and building off of the existing framework for a Social Impact Assessment Tool or a Health Impact Assessment. This can be used to measure the social impact of implementing interventions such as supervised consumption sites, and partnering it with smart city technology will yield higher and more precise results. Implementing the social impact assessment tool to other smart city projects as a measure of success may also be another topic for future research.

\subsection{Conclusions}

The proliferation of smart city technology provides cities and communities the opportunity to find new and innovative solutions to many of the problems that plague them. The Smart Cities Challenge proves that Canadian cities are capable catalysts for urban innovation, and are on par with other global cities that are also testing and implementing smart city technologies. With new technologies, new partnerships and equipped with health data cities can begin to be change-makers and improve the quality of life for its citizens. However, cities need to begin to embed principles of privacy when it comes to protecting citizen health data.

In the increasing datafication of our urban environments, the lines between public and private become blurred. The vacuums and fuzzy areas, are where technology and power have the ability to create unintended side effects that will be borne unto citizens who may not be willing participants. The hard to swallow pill is that smart cities will not 
solve every problem that our cities are constantly grappling with, and it may not the miracle remedy practitioners, researchers and governments hope it will be. This is not to say it will not provide new and exciting ways, of looking at problems. In fact, smart city technologies may prove to be one of the more formidable tools in the civic arsenal.

Understandably, Cities need to embrace partnerships with the private sector for innovation, but also be weary of what partnerships can mean for data sharing and data ownership. Cities also need to understand that collecting data from vulnerable populations that have historically had data used against them, can be unethical and lead to further social disadvantages. But most of all, cities would benefit from understanding that having health at the heart of planning decisions and civic conversations would help improve the lives of it citizens. 


\section{References}

American Planning Association (2016) PAS Essential Info Packet: Planning \& Zoning for Health in the Built Environment. Retrieved from https://www.planning.org/ pas/infopackets/eip38/

Bannerman, S., \& Orasch, A. (2019) Privacy and Smart Cities: A Canadian Survey. McMaster University. Retrieved from https://smartcityprivacy.ca /wp-content/uploads/2019/03/ Bannerman-Orasch-Privacy-and-Smart-Cities-ACanadian-Survey-v2-2019-1.pdf

Barton, H., \& Grant, M. (2011). Urban Planning for Healthy Cities: A Review of the Progress of the European Healthy Cities Programme. Journal of Urban Health: Bulletin of the New York Academy of Medicine, 90(1), s129-s141. doi:10.1007/s11524-011-9649-3

Boulos, M., \& Al-Shorbaji, N (2014). On the Internet of Things, smart cities and the WHO Healthy Cities. International Journal of Health Geographics, 13(10). doi:10.1186/1476-072X-13-10

British Columbia First Nations Data Governance Initiative. (2017). Decolonizing Data: Indigenous Data Sovereignty Primer. Retrieved from http://bcfndgi.squarespace.com /s/Decolonizing-Data-FN_DATA_SOVEREIGNTY_PAPER.docx

Canadian Institute for Health Information (2013). A Performance Measurement Framework for the Canadian Health System. Retrieved from https://secure.cihi.ca/free_products/HSP_Framework_Technical_Report_EN.pdf

Canadian Institute of Planners. (n.d). Healthy Communities Practice Guide. Retrieved from https://www.cip-icu.ca/Files/Resources/CIP-Healthy-CommunitiesPractice-Guide_FINAL_lowre.aspx

Chourabi, H., et al. (2012). Understanding Smart Cities: An Integrative Framework. 45th Hawaii International Conference on System Sciences, Maui, HI, USA. Piscataway, US: IEEE. Retrieved from https://ieeexplore.ieee.org /document/6149291

City of Edmonton. (2018). Smart Cities Challenge Submission. Retrieved from https://smartcities.edmonton.ca/edmontons-approach/

First Nations Information Governance Centre. (2014). Ownership, Control, Access and Possession (OCAP $\left.{ }^{\mathrm{TM}}\right)$ : The Path to First Nations Information Governance. Retrieved from https://fnigc.ca/sites/default/files/docs/ocap_path_to_fn_ information_governance_en_final.pdf 
Haggart, B. (2018). Rationale of a Data Strategy: The Government's Role in Constructing The Data Driven Economy. Centre for International Governance Innovation. Retrieved from https://www.cigionline.org/ articles/governments-role-constructing-data-driven-economy.

Hancock, T. (1993). The Evolution, Impact and Significance of Health Cities/ Healthy Communities Movement. Journal of Public Health Policy, 14(1), 5-18.

Impact Canada. (2018). Applicant Guide. Retrieved from https://impact.canada.ca /en/challenges/smart-cities/applicant-guide

Impact Canada. (2018). Smart Cities Challenge Dashboard. Retrieved from https://www.infrastructure.gc.ca/alt-format/pdf/cities-villes/dashboardtableau-eng.pdf

Kenzer, M. (1998). Healthy cities: a guide to the literature. Environment and Urbanization, 11(1), 201-220.

Kitchin, R. (2016). The ethics of smart cities and urban science. Philosophical Transactions of the Royal Society A: Mathematical, Physical and Engineering Sciences, 374(2083). doi.org/10.1098/rsta.2016.0115

Madakam, S., et al. (2015). Internet of Things (loT): A Literature Review. Journal of Computer and Communications, 3, 164-173. doi.org/10.4236/jcc.2015.35021

Ministry of Municipal Affairs and Housing. (2014). Provincial Policy Statement 2014 under The Planning Act. Retrieved from http://www.mah.gov.on.ca/AssetFactory.aspx?did=10463

Mogstad, A. (2017). Co-creation in Public Service Innovation: a review of how to encourage employee engagement in co-creation. Norwegian University of Science and Technology. Retrieved from https://www.ntnu.edu/documents/139799/1279149990/20+ Article+Final_astridkm_fors\%C3\%B8k_2017-12-07-16-30-25 _Design+Theory+Article+final.pdf/a166fc72-43f1-45d6-be37-2f2a04e54abe

Mohawk Council of Akwesasne. (2018). Smart Akwesasne: Smart Cities Challenge Initial Proposal. Retrieved from http://www.akwesasne.ca/smartakwesasne/

O'Doherty, K., et al. (2016). If you build it, they will come: unintended future uses of organised health data collections. BMC Medical Ethics 17(54). doi:10.1186/s12910-016-0137-x

Obar, J., \& McPhail, B. (2018). Preventing Big Data Discrimination in Canada: Addressing Design, Consent and Sovereignty Challenges. In Data Governance in the Digital Age, 56- 64. Waterloo: Centre for International Governance Innovation

Ontario Professional Planners Institute. (2009). Planning by Design: a healthy communities handbook. Retrieved from https://ontarioplanners.ca/OPPIAssets/Documents/ Calls-to-Action/Healthy_Communities_Handbook_1.pdf 
Ontario Professional Planners Institute. (n.d). Professional Code of Practice. Retrieved from https://ontarioplanners.ca/oppi/about-oppi/professional-code-ofpractice-standards

Public Health Agency of Canada. (2017). Pan-Canadian Health Inequalities Data Tool. Retrieved from https://infobase.phac-aspc.gc.ca/healthinequalities/docs/health-inequalities-map-en.pdf

Public Health Agency of Canada. (2018). Key Health Inequalities in Canada a National Portrait: Executive Summary. Retrieved from https://www.canada.ca/content/dam/phac-aspc/documents/services/ publications/science-research/key-health-inequalities-canada-nationalportrait-executive-summary/hir-executive-summary-eng.pdf

Paskaleva, K, . \& Cooper, I. (2018). Open innovation and the evaluation of internet-enabled public services smart cities. Technovation: The International Journal of Technological Innovation, Entrepreneurship and Technology Management. 78, 4-14. doi.org/10.1016/j.technovation.2018.07.003 Rotenberg, C. (2014). Social Determinants of health for the off-reserve First Nations population, 15 years of age and older, 2012. Statistics Canada. Retrieved from https://www150.statcan.gc.ca/n1/en/pub/89-653-x/89-653-x2016010-eng.pdf ?st=P0099Rcy

Ryan, R., \& Deci, E. (2000). Self-Determination Theory and the Facilitation of Intrinsic Motivation, Social Development, and Wellbeing. American Psychologist, 55(1), 68-78. doi: 10.1037110003-066X.55.1.68

Sanders, E., \& Stappers, P (2008).Co-creation and the new landscape of design. Co-Design, 4(1), 5-18. doi: 10.1080/15710880701875068

Sidewalk Labs. (2018). Digital Governance Proposal for DSAP Consultation. Retrieved from https://waterfrontoronto.ca/nbe/wcm/connect/waterfront/419792658044-442a-9351-e28ef6c76d70/18.10.15_SWT_Draft+Proposals+Regarding +Data+Use+and+Governance.pdf?MOD=AJPERES

Sidewalk Labs. (2019). Living Well on the Waterfront: Imagining the Future of Community Health. Retrieved from https://sidewalktoronto.ca/wp-content/ uploads/ 2019/01/Living-Well-Waterfront.pdf

Solanas, A., et al. (2014). Smart Health: A Content-Aware Health Paradigm within Smart Cities. IEEE Communication Magazine, August 2014, 74-81. doi:10.1109/MCOM.2014.6871673

Statistics Canada. (2018). Using municipal wastewaterto measure Canadians' consumption of cannabis and opioids. Retrieved from https://www150.statcan.gc.ca/n1/pub/13-605-x/2018001/article/54922-eng.htm

Tsouros, A. (2015). Twenty-seven years of the WHO European Healthy Cities movement: a sustainable movement for change and innovation at the local level. Health Promotion International, 30(s1), i3-i7. doi: 10.1093/heapro/dav046 
U.S. Department of Transportation. (n.d). Smart City Challenge. Retrieved from https://www.transportation.gov/sites/dot.gov/files/docs/Smart\% 20City\%20Challenge\%20Lessons\%20Learned.pdf

World Health Organization. (2016). Sustainable Cities: Health at the Heart of Urban Development. Retrieved from https://www.who.int/sustainable-development/ cities/Factsheet-Cities-sustainable-health.pdf

World Health Organization. (2016). Health as the Pulse of the new Urban Agenda. Retrieved from https://apps.who.int/iris/bitstream/handle/10665/ 250367/9789241511445-eng.pdf?sequence=1

Wylie, B. (2018). Governance Vacuums and How Code is Becoming Law. In Data Governance in the Digital Age, 86-90. Waterloo: Centre for International Governance Innovation 